\title{
BMI, Waist to Height Ratio and Waist Circumference as a screening tool for Hypertension in Hospital out Patients: A Cross-Sectional, Non-inferiority study
}

Rajan Shrestha ( $\nabla$ rajanshrestha011@gmail.com )

BP Eye Foundation

Sanjib K. Upadhyay

BP Eye Foundation

Bijay Khatri

BP Eye Foundation

Janak R. Bhattarai

BP Eye Foundation

Manish Kayastha

BP Eye Foundation

Madan P. Upadhyay

BP Eye Foundation

\section{Research Article}

Keywords: obesity, hypertension, Nepal, hospital, outpatient

Posted Date: February 12th, 2021

DOI: https://doi.org/10.21203/rs.3.rs-66161/v4

License: (a) (i) This work is licensed under a Creative Commons Attribution 4.0 International License. Read Full License

Version of Record: A version of this preprint was published at BMJ Open on November 25th, 2021. See the published version at https://doi.org/10.1136/bmjopen-2021-050096. 


\section{Abstract}

Objective The study aimed to determine the burden of obesity, using three commonly employed metrics in the hospital outpatient setting of a developing country as predictors of hypertension through a noninferiority study.

Design A cross-sectional study design was adopted.

Setting This study was conducted in Health Promotion and Risk Factor Screening Service in a tertiary Eye and ENT hospital in a semi-urban area of Nepal.

Participants 2,256 randomly selected $40-69$ years outpatients.

Outcome measures Correlation analysis, the area under the Receiver Operating Characteristic curve, Odds ratios (OR) were calculated between three obesity metrices and hypertension.

Results The prevalence of obesity and overweight by BMI was $16.09 \%$ and $42.20 \%$, respectively; by WHtR was $32.76 \%$, which is two times higher than obesity measured by BMI. High WC was observed among $66.76 \%$ of participants. Female participants had a greater prevalence of high WC $(77.46 \%)$ than males $(53.73 \%)(p<0.001)$. Prevalence of hypertension and pre-hypertension was $40.67 \%$ and $36.77 \%$, respectively. The areas under the curve were significantly higher than 0.5 for BMI $(0.593)$, WHtR $(0.602)$, and WC $(0.610)$.

Conclusion WC correlated well with obesity and hypertension. It also had a higher predicting ability than WHtR and BMI to predict hypertension. WC thus proved to be non-inferior to two other commonly used metrics. It proved superior in detecting obesity in female. This inexpensive and simple non-tension tape measurement may play an important role in the future diagnosis of obesity and the prediction of HTN in resource-constrained settings of developing countries.

\section{Strengths And Limitations Of The Study}

- This is the first study to find out the association between different obesity metrics for screening of hypertension in hospital out patients

- The greater value of this study lies in its ability to signal out that very high proportion of people coming to hospital have overweight /obesity and hypertension that is being missed on a day to day basis in a clinical setting.

- This observational, cross-sectional study cannot infer causal relationship between increase in weight over optimal level and raised blood pressure.

- This hospital based study can not be generalized to represent the whole puplation

\section{Introduction}

The world is rapidly becoming obese. ${ }^{1,2}$ According to the World Health Organization (WHO), obesity rates have tripled since 1975. In 2016, more than 1.9 billion people above 17 years were overweight, and of those, 
over 650 million were obese. ${ }^{3}$ The trends in adult BMI in 200 countries showed that the age-standardized prevalence of obesity increased from $3.2 \%$ to $10.8 \%$ in men, from $6.4 \%$ to $14.9 \%$ in women from 1975 to 2014. ${ }^{4}$ Obesity is known to be strongly associated with hypertension (HTN), heart disease, and diabetes. 5 Worldwide, $23 \%$ of Ischemic heart disease and and $44 \%$ of diabetes have been reported to be associated with overweight and obesity. ${ }^{7}$ Moreover, obesity and HTN are a significant cause of premature death worldwide. ${ }^{8,9}$ WHO has estimated that 1.13 billion people worldwide have HTN; among them, two-thirds are living in LMICs. The rise in burden of NCDs - major killers of the world's population- (such as cardiovascular disease (CVD), diabetes, cancer, and chronic obstructive pulmonary disease) closely parallels rise with the burden of obesity. ${ }^{10,11}$ Most NCDs have obesity as an important risk factor. ${ }^{12,13}$ Recently, obesity has also been reported to be a high risk for morbidity and mortality from COVID-19. ${ }^{14}$ COVID-19 has also been reported to have resulted in a higher incidence of obesity. ${ }^{15}$

Long believed to be a condition affecting affluent countries, obesity is rising even in LMICs. ${ }^{16-18}$ Although it co-exists with malnutrition, more people die of obesity in LMICs than under-nutrition ${ }^{19}$, which is also true for Nepal. ${ }^{20}$ These three pandemics - obesity, under-nutrition, and climate change-represent a Global Syndemic that affects most people in every country and region worldwide. ${ }^{21}$ If the same trend continues, the health system in LMICs would no longer be able to support the future burden of combined onslaught of NCDs and emergent infectious diseases and the effects of climate change. ${ }^{22}$ The fragility of LMICs to control infectious diseases has been well exposed by COVID-19 pandemic. The weak existing health systems have failed in their ability to cope with a new challenge. The emerging epidemics have put patients with NCD at greater risk of death due to their inability to access treatment. The estimated cost of obesity and NCDs to the countries has been estimated to be up to $9.3 \%$ of Gross Domestic Product (GDP). ${ }^{23}$

Nepal has, for long, suffered from undernutrition among its children ${ }^{24}$. However, recent years' overweight and obesity data show an increasing trend for obesity. ${ }^{25-29}$ This is not entirely surprising given that the country is rapidly undergoing urbanization, change in lifestyle, and dietary pattern. ${ }^{25,30}$ Based on the global burden of disease data, the cause of death from NCDs in Nepal has reached 66\% in 2017 from $36.1 \%$ in 2009. ${ }^{31,32}$ Additionally, it is also reported that overweight, obesity, and NCDs occur more frequently among adults who have been undernourished in childhood. ${ }^{33,34}$ This makes children in LMICS more vulnerable to develop obesity in adult life.

Non-communicable diseases country profiles 2018 estimated NCDs account for $66 \%$ of all deaths in Nepal, in which CVD causes 30\% of deaths ${ }^{35}$. The prevalence of HTN tripled in 25 years between 1981 and 2006 and increased to more than double in 10 years (2008 to 2019). ${ }^{29,36} \mathrm{~A}$ similar trend was seen in the prevalence of overweight or obesity, which increased from $7.20 \%$ to $24.30 \%$ between 2008 to $2019 .{ }^{27,29}$ The regional prevalence of HTN, overweight, and obesity in Eastern Nepal in 2011 was 34\%, 28\%, and 32\%, respectively. ${ }^{37}$ 
Like many LMICs, Nepal is battling a triple burden of diseases: communicable, NCDs, and injuries with CVDs being the most common. ${ }^{38}$ Research done in the last decade shows that the conventional risk factors for CVDs are present in a high proportion in the Nepalese population. ${ }^{27}$ In the absence of a routine surveillance or registry system, the actual burden and trend of CVDs in Nepal remains uncertain. Early detection of individuals at high CVD risk is the cornerstone of primary prevention. Simple routine screening methods such as measuring WHtR, WC, blood pressure (BP), which help detect CVDs, are not routinely practiced in LMICs because of heavy patient load and staff shortage.

A simple anthropometric measurement could be used to determine the risk of having hypertension. Several studies show that the different anthropometric measurements of obesity can predict CVDs risk, such as HTN, though the best anthropometric measurement as a predictor of HTN remains contentious and controversial. BMI, WC, and WHtR are commonly used anthropometric screening tools to predict HTN and other CVDs. ${ }^{39}$ Some studies have suggested that WC and WHtR may be better predictors for HTN and CVD risk, $^{40-45}$ while other studies suggest that BMI and WC as better predictors of HTN. ${ }^{46-48}$ A meta-analysis suggested that WC is a better predictor for CVDs risks such as HTN and recommended that it should be used in clinics and research. 49

Most reported studies on obesity, HTN, and their association had been conducted in community settings. There is a paucity of hospital data on the burden of obesity, HTN, and an association between them in outpatient hospital settings of LMICs. So, this study was designed to find out burden of obesity and HTN among patients attending hospital and compare the ability of three different currently available anthropometric measurements to predict HTN in the hospital outpatients in low-income setting.

\section{Methods}

\section{Study design and study population}

This hospital-based cross-sectional descriptive study was conducted from June to December 2019 at Hospital for Children Eye, ENT and Rehabilitation Services (CHEERS), Bhaktapur, Nepal. We used systematic random sampling to select the participants. Every third consecutive participant aged 40 to 69 visiting the Health Promotion and Risk Factor Screening (HP-RFS) service of CHEERS during the study period constituted the study population. The sample size calculation was based on hypertension 's prevalence of $46.7 \%(P)^{28}$. Margin of error considered as 5\% (D), 95\% confidence level $(Z=1.96)$ and $80 \%$ response rate. The formulae used for sample size calculation is $N=\left(Z^{2 \star} P(1-P)\right) /\left(D^{2}\right)$. The calculated sample size is multiplied by the number of domains to obtain the final sample size. The numbers of domains were decided to be two age groups and two genders. Based on the calculation, the minimum sample size required was 1,913. All participants were informed about the purpose of the screening service; informed consent was 
obtained before anthropometric measurements. Pregnant women and people unable to stand properly were excluded from data analysis for this study.

\section{Anthopometric measurements}

A standardized protocol is followed at the hospital for anthropometric measurements. A community medicine auxiliary (CMA) was trained on an existing protocol for obtaining anthropometric measurements for height, weight, WC, and BP. The height, weight, and WC were measured on a portable digital weighing scale (Equinox weighing scale), stadiometer (Prestige stadiometer), and constant tension tape, respectively. The participants were asked to remove bulky clothes, shoes, and cap before taking measurements. The WC in $\mathrm{cm}$ was measured at the midpoint between the lower edge of the rib cage and the iliac crest after a full expiration. BMI was calculated as weight $(\mathrm{kg})$ divided by height in meter squared $\left(\mathrm{m}^{2}\right)$. The WHtR was calculated as WC in cm divided by height in $\mathrm{cm}$. Besides anthropometric measurements, socio-demographic information and history of HTN (anti-HTN medication) was also enquired.

The standard value for WHtR was considered as 'no increased risk' (WHtR <0.5); 'increased risk' (WHtR $\geq 0.5$ to $<0.6)$ and 'very high-risk' (WHtR $\geq 0.6)$. Similarly, for WC, WC=90 cm for male and $W C=80 \mathrm{~cm}$ for females was considered as 'cutoff value' 50 . The standard weight status categories associated with BMI range of $18.5-24.9 \mathrm{~kg} / \mathrm{m}^{2}$ were considered normal, whereas 25.0 to $29.9 \mathrm{~kg} / \mathrm{m} 2$ and $30 \mathrm{~kg} / \mathrm{m} 2$ were considered overweight and obese ${ }^{51}$.

BP of the participants was measured by aneroid sphygmomanometer with adult cuff size. Participants were asked to sit quietly for 15 mins, leg uncrossed in a comfortable position. BP was measured in the left arm, placing the cuff at the heart level, placing the artery mark in the cuff at the level of the brachial artery. Blood pressure in participants with initial high blood pressure was re-measured after 15 minutes rest.

\section{Statistical analysis}

The participants were classified as hypertensive if their systolic blood pressure (SBP) was $140 \mathrm{mmHg}$ or higher and/or diastolic blood pressure (DBP) was $90 \mathrm{~mm} \mathrm{Hg}$ or higher and pre-hypertensive (Pre-HTN) if SBP levels were between 120-139 mmHg and/or DBP levels were between $80-89 \mathrm{mmHg}$. The participants were also considered hypertensive if they were taking antihypertensive medication, even though their BP was normal at the time of measurement. The participants who did not fit in all of the above categories were considered as normotensive.

Collected data were instantly entered in Excel (MS Office 2010). Data analysis was done using R language, version 4.0.0. Continuous variables are shown as the mean, standard deviation (SD), and categorical variables as frequency and percentage. Independent sample t-test was done to compare mean values of continuous variable between different groups. We used logistic regression analysis to find the effect of socio-demographic variables, different obesity metrics separately, and adjusted odds ratio (AOR) for hypertensive compared to the non-hypertensive group was analyzed by entering age and sex in a model with 
socio-demographic variables in separate different analysis models. Odds ratios (OR) were also reported in $95 \%$ Confidence Interval. We calculated correlation analysis and calculated Spearman's product-moment correlation coefficient. The area under Receiver Operating Characteristic (ROC) curve of BMI, WHtR and WC on predicting hypertension with $95 \%$ confidence interval $(\mathrm{Cl})$ was calculated. The $\mathrm{Cl}$, which did not include 0.5 were considered to indicate significant results, The $p$-value $<0.05$ was considered significant for all tests.

\section{Results}

This study included 2,256 randomly selected participants from 6,769, persons 40-69 years visiting Health Promotion and Riskfcators assessment (HP-RFS) service at CHEERS from June to December 2019. The mean (SD) age of the participants was 51.75 years. The visitors to this specialty hospital came to the hospital for eye and ENT consultations.

The mean (SD) of the measurement in different domains are shown in table 1. The mean (SD) BMI was $25.29(3.81) \mathrm{kg} / \mathrm{m}^{2}$ and $26.72(4.44) \mathrm{kg} / \mathrm{m}^{2}$ for male and female participants respectively $(\mathrm{p}<0.01)$. The mean BMI was observed to gradually decrease with advancing age in both male and female participants. The mean (SD) WHtR was $0.56(0.06)$ and $0.58(0.08)$ for male and female $(p<0.01)$ respectively. Similarly, the mean (SD) WC was $90.96(10.32) \mathrm{cm}$ and $88.24(10.94) \mathrm{cm}$ for males and females $(p<0.01)$ respectively.

Table 1: Mean (SD) of different anthropometric measurements according to age and gender

\begin{tabular}{|c|c|c|c|c|c|c|c|c|c|c|}
\hline & \multicolumn{7}{|c|}{ Age group (Years) } & \multicolumn{3}{|l|}{ Gender } \\
\hline & \multicolumn{3}{|c|}{$40-54$} & $55-69$ & \multirow{2}{*}{$\begin{array}{c}\mathrm{p}- \\
\text { value }\end{array}$} & \multicolumn{3}{|c|}{ Male } & Female & \multirow{2}{*}{$\begin{array}{r}\mathrm{p}- \\
\text { value* }\end{array}$} \\
\hline & Mean & SD & Mean & $\overline{S D}$ & & Mean & SD & Mean & SD & \\
\hline SBP (mmHg) & 118.46 & 14.96 & 122.77 & 16.49 & $<0.01$ & 121.47 & 15.50 & 118.90 & 15.74 & $<0.01$ \\
\hline DBP (mmHg) & 79.21 & 10.74 & 79.39 & 10.25 & 0.69 & 79.98 & 10.67 & 78.69 & 10.43 & $<0.01$ \\
\hline Weight (KG) & 65.55 & 10.81 & 61.58 & 11.41 & $<0.01$ & 67.41 & 11.15 & 61.32 & 10.48 & $<0.01$ \\
\hline Height (CM) & 157.60 & 8.84 & 155.47 & 9.15 & $<0.01$ & 163.19 & 7.23 & 151.54 & 6.62 & $<0.01$ \\
\hline $\begin{array}{l}\text { WC } \\
\text { (CM) }\end{array}$ & 89.51 & 10.38 & 89.40 & 11.36 & 0.83 & 90.96 & 10.32 & 88.24 & 10.94 & $<0.01$ \\
\hline WHtR & 0.57 & 0.07 & 0.58 & 0.08 & 0.02 & 0.56 & 0.06 & 0.58 & 0.08 & $<0.01$ \\
\hline BMI & 26.41 & 4.08 & 25.50 & 4.41 & $<0.01$ & 25.29 & 3.81 & 26.72 & 4.44 & $<0.01$ \\
\hline
\end{tabular}

* independent sample t-test

Prevalence of Obesity and overweight

The prevalence of obesity $\left(\mathrm{BMI} \geq 30 \mathrm{~kg} / \mathrm{m}^{2}\right.$ ) and overweight (BMI= 25.0 to $29.9 \mathrm{~kg} / \mathrm{m}^{2}$ ) was $16.09 \%$ and $42.20 \%$ respectively. Female participants had higher prevalence of obesity $(21.4 \%)$ than male $(9.6 \%)(p-$ value $<0.001$ ). The observed prevalence of overweight using $\mathrm{BMI}$, among males and females, was $42.8 \%$ and 
$41.7 \%$, respectively, was statistically not significant ( $p$-value $=0.6121)$. Younger age groups had a significantly higher prevalence ( $p$-value $<0.001$ ) of overweight and obesity in both genders. Table 2 summarizes obesity and overweight according to gender and age groups. The odds ratio for being obese, comparing females to males was 2.58 (95\% Cl:2.01-3.31), and that of being overweight was 0.95 (95\% Cl:0.0.81-1.13).

The prevalence of obesity by WHtR was $32.76 \%$, which is higher than obesity measured by BMI. Female participants had a higher prevalence $(40.1 \%)$ than male participants $(23.8 \%)$, and the difference is statistically significant ( $p$-value $<0.001$ ). Age group $40-54$ years had a significantly higher prevalence of abdominal obesity among female participants ( $37.59 \%$ vs $44.52 \%, p=0.0195)$, which was not different among male participants $(23.96 \%$ vs $23.66 \%, p=0.974)$.

High WC was observed among $66.76 \%$ of participants; female participants had much higher prevalence $(77.46 \%)$ than males $(53.73 \%)(p<0.001)$. Thus, WC detected the highest prevalence of obesity compared to the other two metrics; the prevalence is not significantly different in-between age groups.

\section{Table 2: BMI, WHtR and WC classification according to age and sex}

\begin{tabular}{|c|c|c|c|c|c|c|c|c|c|c|}
\hline \multicolumn{2}{|c|}{ Characteristic } & \multirow[t]{2}{*}{$\mathbf{n}$} & \multicolumn{3}{|c|}{ BMI } & \multicolumn{3}{|c|}{ WHtR } & \multicolumn{2}{|c|}{$\mathrm{WC}^{\#}(\mathrm{CM})$} \\
\hline & $\begin{array}{l}\text { Age } \\
\text { Group } \\
\text { (Years) }\end{array}$ & & $\begin{array}{l}\geq 30.0 \\
\mathrm{~kg} / \mathrm{m}^{2}\end{array}$ & $\begin{array}{r}25.0- \\
29.9 \\
\mathrm{~kg} / \mathrm{m}^{2}\end{array}$ & $\begin{array}{l}<25.0 \\
\mathrm{~kg} / \mathrm{m}^{2}\end{array}$ & 0.60 & $\begin{array}{r}0.50- \\
0.59\end{array}$ & 0.50 & $\begin{array}{l}\geq \text { cut } \\
\text { off }\end{array}$ & $\begin{array}{l}<\text { cut } \\
\text { off }\end{array}$ \\
\hline All & & 2,256 & 16.09 & 42.20 & 41.71 & 32.76 & 53.19 & 14.05 & 66.76 & 33.24 \\
\hline Male & $\underset{40-54}{\text { All age }}$ & $\begin{array}{l}1,048 \\
634\end{array}$ & $\begin{array}{l}9.60 \\
10.88\end{array}$ & $\begin{aligned} & 42.80 \\
& 47.48\end{aligned}$ & $\begin{array}{r}47.50 \\
41.64\end{array}$ & $\begin{array}{l}23.80 \\
23.65\end{array}$ & $\begin{array}{l}60.00 \\
60.25\end{array}$ & $\begin{array}{l}16.20 \\
16.09\end{array}$ & $\begin{array}{l}53.73 \\
55.68\end{array}$ & $\begin{array}{l}46.27 \\
44.32\end{array}$ \\
\hline & $55-69$ & 384 & 7.55 & 35.16 & 57.29 & 23.96 & 59.63 & 16.41 & 50.52 & 49.48 \\
\hline Female & All age & 1,238 & 21.40 & 41.70 & 36.90 & 40.10 & 47.60 & 12.30 & 77.46 & 22.54 \\
\hline & $40-54$ & 782 & 21.74 & 44.37 & 33.89 & 37.59 & 50.00 & 12.40 & 77.75 & 22.25 \\
\hline & 55-69 & 456 & 20.83 & 37.06 & 42.10 & 44.52 & 43.42 & 12.06 & 76.97 & 23.06 \\
\hline
\end{tabular}

\# cut off value of WC for male is $90 \mathrm{~cm}$ and for female is $80 \mathrm{~cm}$ Prevalence of Hypertension

The prevalence of pre-HTN and HTN, including unadjusted and adjusted odds ratios of different categories, are shown in table 3. The overall prevalence of HTN and pre-HTN was $40.67 \%$ and $36.77 \%$, respectively. Male participants had a slightly higher prevalence of HTN (42.72\%) than female participants $(39.00 \%)$. The prevalence of HTN for both genders was found to increase as the age group increased. Prevalence of PreHTN was found to be $36.77 \%$ and $35.11 \%$ among male and female participants. A staggering $81.50 \%$ of male and $74.11 \%$ of female participants had either established HTN or pre HTN (HTN suspects). A 
concerning finding was that among 916 participants with HTN, 57.4\% didn't know they had raised BP before this study.

Age-adjusted AOR for being hypertensive for females compared to males was 0.86 (95\% Cl:0.72-1.02), and sex sex-adjusted AOR for being hypertensive was 1.61 (95\% Cl: 1.35-1.91) for the age group 55-69 compared to age group 40-54.

Table 3: HTN, socio-demographic variables, and risk factors

$\begin{array}{cccc}\text { Pre } & \text { HTN } & \text { Unadjusted Odds Ratio } & \text { Adjusted Odds ratio* for } \\ \text { HTN } & \text { n } & \text { for HTN (95\% CI) } & \text { HTN (95\% CI) } \\ \text { n } & (\%) & & \\ (\%) & & & \end{array}$

\begin{tabular}{|c|c|c|c|c|c|}
\hline All & & $\begin{array}{l}828 \\
(36.77)\end{array}$ & $\begin{array}{l}916 \\
(40.67)\end{array}$ & & \\
\hline Sex & Female & 434 & 482 & 1 & 1 \\
\hline & Male & $\begin{array}{l}394 \\
\text { (38.78) }\end{array}$ & $\begin{array}{l}434 \\
(42.72)\end{array}$ & $0.86(0.72-1.01)$ & $0.86(0.72-1.02)$ \\
\hline Age group & $40-54$ & 544 & 514 & 1 & 1 \\
\hline & $55-69$ & $\begin{array}{l}(38.50) \\
284\end{array}$ & $\begin{array}{l}(36.38) \\
402\end{array}$ & $1.61(1.35-1.91)$ & $1.61(1.35-1.91)$ \\
\hline BMI & $\begin{array}{l}<\quad 25 \\
\mathrm{~kg} / \mathrm{m}^{2}\end{array}$ & $\begin{array}{l}337 \\
\text { (35.93) }\end{array}$ & $\begin{array}{l}312 \\
(33.26)\end{array}$ & 1 & 1 \\
\hline & $\begin{array}{l}\geq 25 \\
\mathbf{k g} / \mathrm{m} 2\end{array}$ & $\begin{array}{l}491 \\
(37.37)\end{array}$ & $\begin{array}{l}604 \\
(45.97)\end{array}$ & $1.74(1.43-2.03)$ & $1.89(1.58-2.26)$ \\
\hline WHtR & $<0.5$ & 93 & & 1 & 1 \\
\hline & $\geq 0.5$ & $\begin{array}{l}\text { (31. } 735 \\
(37.52)\end{array}$ & $\begin{array}{l}833 \\
(42.52)\end{array}$ & $1.87(1.43-2.45)$ & $1.92(1.46-2.52)$ \\
\hline $\mathrm{WC}^{\#}(\mathrm{CM})$ & $<$ & 281 & 235 & 1 & 1 \\
\hline & $\geq$ & $\begin{array}{l}547 \\
\text { (36.37) }\end{array}$ & $\begin{array}{l}681 \\
(45.28)\end{array}$ & $1.81(1.50-2.17)$ & $2.02(1.66-2.45)$ \\
\hline
\end{tabular}

\# cut off value of WC for male is $90 \mathrm{~cm}$ and for female is $80 \mathrm{~cm}$

* AOR were adjusted for age and sex variables

Obesity and HTN

The prevalence of HTN among the participants with $\mathrm{BMI} \geq 25 \mathrm{~kg} / \mathrm{m}^{2}, \mathrm{WHtR} \geq 0.5$, and WC $\geq$ cutoff value was $45.97 \%, 42.52 \%$, and $45.28 \%$, respectively. Not surprisingly, a higher prevalence of HTN was found among participants with either overweight or obesity than participants with average weight ( $P$-value $<0.001)$. Age and sex-adjusted AOR for being hypertensive among high BMI, WHtR, and WC than normal; were 1.89 (1.58-2.26), 1.92 (1.46-2.52), and 2.02 (1.66-2.45), respectively indicating WHtR and WC's ability to predict HTN than BMI better.

Table 4 shows the correlation between BMI, WC, WHtR, BP, and Age, including level of significance. A strong positive correlation $(r=0.682, P<0.01)$ was found between WC and BMI. WC had highest positive correlation $(r=0.188, p<0.01)$ with SBP than other two metrics. However, BMI had highest positive correlation $(r=0.214$, 
$p<0.01)$ with HTN than other metrics. The relationship between all three anthropometric metrics and SBP was found higher than with DBP.

\begin{tabular}{lllllll}
\hline \multicolumn{6}{l}{ Table 4. Correlation between BMI, WHtR, WC, SBP, DBP, and Age } \\
\hline & BMI & WC (CM) & WHtR & SBP (mmHg) & DBP (mmHg) & Age (Years) \\
\hline BMI & 1 & $0.682^{* *}$ & $0.770^{* *}$ & $0.154^{* *}$ & $0.214^{* *}$ & $-0.120^{* *}$ \\
WC (CM) & $0.682^{* *}$ & 1 & $0.884^{* *}$ & $0.188^{* *}$ & $0.192^{* *}$ & -0.004 \\
WHtR & $0.770^{* *}$ & $0.884^{* *}$ & 1 & $0.168^{* *}$ & $0.183^{* *}$ & $0.054^{*}$ \\
SBP (mmHg) & $0.154^{* *}$ & $0.188^{* *}$ & $0.168^{* *}$ & 1 & $0.726^{* *}$ & $0.137^{* *}$ \\
DBP (mmoHg) & $0.214^{* *}$ & $0.192^{* *}$ & $0.183^{* *}$ & $0.726^{* *}$ & 1 & -0.007 \\
Age (Years) & $-0.120^{* *}$ & -0.004 & $0.054^{*}$ & $0.137^{* *}$ & -.007 & 1 \\
\hline
\end{tabular}

* Correlation is significant at the 0.05 level.

** Correlation is significant at the 0.01 level.

Receiver Operating Characteristic (ROC) analyses were used to determine the relative ability of the threeobesity metrics to predict HTN as depicted in Fig. 1 and Table 5. The areas under the curve (AUC) were significantly higher than 0.5 for BMI $(0.593,95 \% \mathrm{Cl}: 0.569-0.616)$, WC $(0.610,95 \% \mathrm{Cl}: 0.586-0.633)$ and WHtR $(0.602,0.595 \% \mathrm{Cl}: 78-0.625)$. In both gender and all age groups, AUC is significantly higher than 0.5 $(P<0.01)$

\begin{tabular}{|c|c|c|c|c|}
\hline \multicolumn{5}{|c|}{ Table 5. Sex and Age-specific comparisons of the area under ROC curves of BMI, WC, and } \\
\hline & & BMI & WC (CM) & WHtR \\
\hline All & & $0.593(0.569-0.616)^{*}$ & $0.610(0.586-0.633)^{*}$ & $0.602(0.578-0.625)^{*}$ \\
\hline Sex & Male & $0.620(0.585-0.654) *$ & $.586-0.655) *$ & $0.629(0.595-0.664) *$ \\
\hline & Female & 0.581 (0.549-0.614)* & $566-0.630)^{*}$ & $0.590(0.558-0.623) *$ \\
\hline Age (Years) & $40-54$ & $0.600(0.570-0.631)^{*}$ & $0.606(0.563-0.625) *$ & $0.594(0.563-0.625)^{*}$ \\
\hline & $55-69$ & $0.610(0.572-0.648) *$ & $0.620(0.583-0.658) *$ & $0.609(0.572-0.647) *$ \\
\hline
\end{tabular}

* Correlation is significant at the 0.01 level.

\section{Discussion}

This descriptive study is an outcome of an opportunistic Risk Factor Screening (RFS) for NCDs, obesity, and HTN at the Health Promotion Unit of a tertiary Eye and ENT hospital in Bhaktapur, Nepal.

The overall prevalence of obesity using BMI in this study was $16.09 \%$, which is higher than obesity prevalence reported in the 2019 NCD Risk Factors STEPS survey Nepal, where only $5.42 \%$ of the same agegroup were reported be obese ${ }^{29}$. This might be due to different due to settings of the two studies as this study was done in semi-urban area of Kathmandu valley, whereas STEP survey covered both urban and rural areas. Additionally, using BMI, we found that more than two in ten $(21.40 \%)$ women and nearly one in ten $(9.60 \%)$ men coming to the hospital were obese, which is nearly double the previously reported values in the 
Nepal Demographic and Health (DHS) survey of 2016, for both genders (women: 9.5\% and men: 5.1\%) [24]. Again, these are not comparable because of the different settings in which these studies were done and also different parameters used, but may be indicative of an inceasing trend.

Using International Diabetes Federation recommended cutoff points for south Asians ${ }^{50}$ (male $90 \mathrm{~cm}$ and female $80 \mathrm{~cm}$ ) for WC, two-thirds $(66.76 \%)$ of participants were found to be obese as opposed to only $16.09 \%$ measured with BMI. More than three-quarters (77.46\%) of women and over half $(53.73 \%)$ of men were obese in our study.

The overall prevalence of abdominal obesity by WHtR was $32.76 \%$, with higher prevalence among women (40.1\%) than men (23.8\%). This indicates that obesity measured by WHtR missed a significant proportion of the most important CVD risk factor. Also, WC was able to detect more obesity cases than either BMI or WHtR proving itself superior to the other two metrics.

The observed higher prevalence of body fat in women than men, using all three obesity metrics in our study, is supported by other studies. ${ }^{17,25,28}$ The reported increase in abdominal obesity with each pregnancy independent of total body fat ${ }^{54}$ may explain higher abdominal obesity among women.

Regardless of the metrics used, this study shows a higher prevalence of obesity among Hospital OPD patients, indicating that screening for obesity in this setting has a higher potential to detect a larger number of people with obesity than in community settings; the latter is however, essential for population-based data.

The higher prevalence of obesity in the present study may be due to study design, a selection bias as people reporting to hospitals may also have some or other conditions which could have obesity at the background of their illness. Examined within the larger context of non-utilization of health services, these people may be the ones with better health-seeking behavior, therefore, not truly representative of the community. However, the fact that hospitals draw visitors from their local community would confirm the presence of a high prevalence of this risk factor in the local community. This would need to be confirmed through multi-centric studies in different regions.

To the best of our knowledge, this is the first hospital OPD based data on obesity prevalence from Nepal.

The prevalence of HTN in our study was 40.67\%, and men had a slightly higher prevalence of HTN (42.72\%) than women (39.00\%). Our findings are comparable to the 2019 STEPS survey Nepal and 2016 Nepal DHS, where the prevalence of HTN was $40.91 \%$ and $32.6 \%$, respectively. ${ }^{26}$ In the present study and the other two nation-wide surveys, the prevalence of HTN increased with increasing age. One in three participants with pre- 
HTN detected in this study would be an important finding indicating the possible group of patients who could turn into hypertensive in near future, if not intervened. A disturbing finding of this study was that $57.6 \%$ of hypertensive patients, who presumably had betterhealth-seeking behavior, didn't know that they had raised BP before this study. This should alert hospital leaders to launch health promotion programs to raise awareness about HTN in hospitals and their surrounding community.

Although the prevalence of obesity was higher in the present study than nation-wide survey; however, the prevalence of HTN is almost similar to community-based national surveys. Obesity is an earlier event in the evolution of HTN, which develops over a period of time with progressive deposition of atheromatous materials in the blood vessels of people who, by and large, have increased body fat, although HTN can occur in thin people as well. It would, therefore be reasonable to assume that obesity is a precursor of non-genetic HTN and therefore develops earlier than HTN. In this regard, we propose to follow a cohort of our participants who have obesity but did not have raised BP.

At our hospital, we refer persons found to be overweight or obese to a counselor in the next room who advises them for appropriate life style modifications and if necessary, refers to Exercise Medicine unit and to an in-house General Practitioner for any associated disease conditions.

\section{Obesity and Hypertension}

In the present study, using all metrics, a significantly higher prevalence of HTN was found among participants with either overweight or obesity compared to participants with normal weight. Also, WC participants greater than the cutoff value were twice $(2.02 ; 95 \% \mathrm{Cl}: 1.66-2.45)$ likely to be hypertensive than people with normal WC. This is supported by several studies in differrent countries (Italy, USA, India). ${ }^{52-55}$

This study, also found a statistically significant positive correlation between all the anthropometric metrics and both SBP and DBP. These findings are in agreement with other studies with different populations which support a strong relationship between different obesity metrics and BP across developed and developing countries. The Olivetti Heart Study also showed a weak, but significant and positive correlation between WC and $\operatorname{SBP}(r=0.191, P<0.001)$, and DBP $(r=0.166, P<0.001)$ as well. ${ }^{56}$

An important finding of the present study is that while BMI, WC, and WHtR were all predictors of HTN, WC was the best predictor overall and BMI the least, WHtR being better predictor for males. However, WC was better for females, both genders combined, and the age-group in the present study. Other studies have also shown that both WC or WHtR is a better predictor for HTN than BMI. A Brazilian cohort study also showed that WC and WHtR were better predictors of HTN in adults over 18, with an AUC value of 0.66 and 0.64 , 
respectively, while BMI was 0.62. However, the associations were only significant for women as in our study. ${ }^{55}$ The study in India showed AUC values as $0.694,0.667$ and 0.634 for WHtR, WC and BMI respectively. ${ }^{57}$ The study done in eastern India also showed AUC values of BMI, WC, and WHtR were 0.654 , 0.676, and 0.693, respectively, indicating WC and WHtR as a better predictor for HTN than BMI. ${ }^{58}$

The greater value of this study lies in its ability to signal out very high prevalence of obesity and HTN in people coming to a tertiary care hospital, that is being missed on a day to day basis in clinical setting of busy hospitals of LMIcs with inadequate health resources.

Although prospective, this is still a single-center, observational, cross-sectional study design, hence a causal relationship between an increase in weight over the optimal level and raised BP can not be established. The study was performed with the limited objective of finding an inexpensive, simple enough measure of obesity which could be conducted by even non-medical personnel.

\section{Conclusions}

The present study showed that WC measured with an inexpensive non-tension tape was not inferior to BMI and WHtR as metrics for obesity detection. Obesity thus detected, correlated well with HTN; had higher predicting ability for HTN than two other metrics (WHtR and BMI). Because of its low cost, simplicity of measurement, and its better ability to predict HTN, it may become a more frequently used tool in health facilities.

However, validation through larger studies in different settings (multicenter studies) is required for further confirmation before becoming a universal tool for routine and research use at the national level. Regardless of the anthropometric metrics to measure obesity, the hospital setting is an opportune venue to screen overweight, obesity, and hypertension, which are major risk factors of NCDs. This is not standard practice as yet in many LMICs.

Finally, this study is an outcome of CHEERS' evolving practice model of proactive, person-centered care, followed at this hospital, which is an approach to reorienting the health system by incorporating health promotion activities in contrast to the mainstream health system's current practice of disease-focused, organ-centered, fragmented care.

\section{List Of Abbreviations}

AOR: $\quad$ Adjusted Odds Ratio

AUC: $\quad$ Area Under the Curve

BMI: $\quad$ Body Mass Index 
BP: $\quad$ Blood Pressure

CHEERS: Hospital for Children Eye ENT and Rehabilitation Services

Cl: $\quad$ Confidence Interval

CM: $\quad$ Centimeter

CMA: $\quad$ Community Medicine Assistant

CVDs: $\quad$ Cardio Vascular Diseases

DBP: $\quad$ Diastolic Blood Pressure

DHS: $\quad$ Demographic and Health Survey

ENT: $\quad$ Ear Nose Throat

GDP: $\quad$ Gross Domestic Product

HTN: Hypertension

RP-RFS: $\quad$ Health Promotion and Risk Factor Screening

KG: Kilograms

LMICs: $\quad$ Low- and Middle-Income Countries

NCDs: $\quad$ Non-Communicable Diseases

ROC: $\quad$ Receiver Operating Characteristic

SBP: $\quad$ Systolic Blood Pressure

SD: $\quad$ Standard Deviation

WC: $\quad$ Waist Circumference

WHO: $\quad$ World Health Organization

WHtR: $\quad$ Waist to Height Ratio

\section{Declarations}

Acknowledgments We are grateful to Ms. Jeera Budha, who was involved in data collection. We would like to express our sincere thanks to CHEERS Hospital administration for allowing us to conduct in this study and giving permission to submit for publication. 
Authors Contributions RS and MPU designed the study. RS, BK, JRB were involved in proposal writing. RS and BK involve in data analysis. RS, BK, SKU were involved in drafting the manuscript. RS, BK, MPU, JRB, $S K U$, and MK are involved in critical analysis and review of manuscript. All authors have read the manuscript carefully and approved its submission.

Funding Statement No funding received for this study

Competing Interest None decleared

Ethical approval This study was approved by Nepal Health Research Council (207/2019). Informed consent was taken from every participant before the interview and anthropometric measurement. Participation in this study was voluntary.

Data Availability The datasets used and/or analyzed during the current study are available from the corresponding author on reasonable request.

\section{References}

1. Ng M, Fleming T, Robinson M, et al. Global, regional, and national prevalence of overweight and obesity in children and adults during 1980-2013: a systematic analysis for the Global Burden of Disease Study 2013. Lancet 2014;384(9945):766-81. Publisher Site _ Google Scholar

2. Popkin BM. The world is fat. Sci Am 2007;297(3):88-95. Google Scholar

3. Obesity and overweight 2020. https://www.who.int/news-room/fact-sheets/detail/obesity-andoverweight. Accessed on 1 April 2020.

4. NCD Risk Factor Collaboration (NCD-RisC). Trends in adult body-mass index in 200 countries from 1975 to 2014: a pooled analysis of 1698 population-based measurement studies with $19 \cdot 2$ million participants. Lancet. 2016;387(10026):1377-96. Publisher Site Google Scholar

5. Hall JE, Kuo JJ, da Silva AA, et al. Obesity-associated hypertension and kidney disease. Curr Opin Nephrol Hypertens. 2003;12(2). Google Scholar

6. Rahmouni K, Correia Marcelo LG, Haynes William G, et al. Obesity-Associated Hypertension. Hypertension. 2005;45(1):9-14. Publisher Site Google Scholar

7. Global health risks: mortality and burden of disease attributable to selected major risks. 2009. Report No.: 978924156387 1. Publisher Site Google Scholar

8. Prospective Studies Collaboration. Body-mass index and cause-specific mortality in 900000 adults: collaborative analyses of 57 prospective studies. Lancet. 2009;373(9669):1083-96. Publisher Site Google Scholar

9. Hypertension 2019. https://www.who.int/news-room/fact-sheets/detail/hypertension. Accessed on 1 September 2020.

10. Hannah Rithie, Max Roser. "Obesity and BMI": Our World in Data; 2019. https://ourworldindata.org/obesity. Accessed on 15 April 2020. 
11. Max Roser, Hannah Ritchie. Burden of Disease: Our World in Data; 2019. https://ourworldindata.org/burden-of-disease. Accessed on 15 April 2020.

12. Banjare JB, Bhalerao S. Obesity associated non-communicable disease burden. Int J Health Allied Sci. 2016;5(2):81. Google Scholar

13. Global status report on non-communicable diseases. 2014. https://apps.who.int/iris/bitstream/handle/10665/148114/9789241564854_eng.pdf.

14. Yadav R, Aggarwal S, Singh A. SARS-CoV-2-host dynamics: Increased risk of adverse outcomes of COVID-19 in obesity. Diabetes Metab Syndr. 2020;14(5):1355-60. Publisher Site Google Scholar

15. Abbas AM, Fathy SK, Fawzy AT, et al. The mutual effects of COVID-19 and obesity. Obes Med. 2020;19:100250.. Publisher Site Google Scholar

16. Bhurosy T, Jeewon R. Overweight and Obesity Epidemic in Developing Countries: A Problem with Diet, Physical Activity, or Socioeconomic Status? ScientificWorldJournal. 2014;2014:964236. Publisher Site Google Scholar

17. Ford ND, Patel SA, Narayan KMV. Obesity in Low- and Middle-Income Countries: Burden, Drivers, and Emerging Challenges. Annu Rev Public Health. 2017;38(1):145-64. Publisher Site Google Scholar

18. Popkin BM, Slining MM. New dynamics in global obesity facing low- and middle-income countries. Obes Rev. 2013;14(S2):11-20. Publisher Site Google Scholar

19. Basnyat B, Rajapaksa LC. Cardiovascular and infectious diseases in South Asia: the double whammy. BMJ. 2004;328(7443):781. Publisher Site Google Scholar

20. Khadaee GH, Saeidi M. Increases of Obesity and Overweight in Children: an Alarm for Parents and Policymakers. Int J Pediatr. 2016;4(4):1591-601. Publisher Site Google Scholar

21. Swinburn BA, Kraak VI, Allender S, et al. Global Syndemic of Obesity, Undernutrition, and Climate Change: The Lancet Commission report. Lancet. 2019;393(10173):791-846. Publisher Site Google Scholar

22. Boutayeb A, Boutayeb S. The burden of non communicable diseases in developing countries. Int J Equity Health. 2005;4(1):2. Publisher Site Google Scholar

23. Waters HU, Graf MA. America's obesity crisis. The Health and Economic Costs of Excess Weight. Santa Monica, California: Milken Institute. 2018 Oct. Publisher Site Google Scholar

24. Joshi PC. Malnutrition in children: A serious public health issue in Nepal. Health Prospect: Journal of Public Health 2013;11:61-62. Publisher Site Google Scholar

25. Vaidya A, Shakya S, Krettek A. Obesity prevalence in Nepal: public health challenges in a low-income nation during an alarming worldwide trend. International journal of environmental research and public health. 2010;7(6):2726-44. Publisher Site Google Scholar

26. Ministry of Health, New ERA, ICF. Nepal Demographic and Health Survey 2016. Kathmandu, Nepal: $\mathrm{MOH} / \mathrm{Nepal}$, New ERA, and ICF; 2017. Publisher Site

27. Ministry of Health and Population, Government of Nepal, Society for local integrated Development Nepal and WHO. WHO STEPS Surveillance: Non Communicable Disease Risk Factor Survey. 2008. Publisher Site 
28. Aryal KK, Neupane S, Mehata S, et al. Non communicable diseases risk factors: STEPS Survey Nepal 2013. Kathmandu: Nepal Health Research Council. 2014. Publisher Site

29. Dhimal M, Bista B, Bhattarai S, et al. Report of Non Communicable Disease Risk Factors: STEPS Survey Nepal 2019. Kathmandu, Nepal: Nepal Health Research Council (NHRC); 2020. Publisher Site

30. Subedi YP, Marais D, Newlands D. Where is Nepal in the nutrition transition? Asia Pacific journal of clinical nutrition. 2015. Publisher Site Google Scholar

31. Nepal Health Research Council, MoHP, Monitoring Evaluation and Operational Research. Nepal Burden of Disease 2017: A country Report based on the Global Burden of Disease 2017 Study. Kathmandu, Nepal. 2019. Publisher Site

32. Nepal Health Research Council. Assessment of Burden of Disease in Nepal 2009. Kathmandu, Nepal; 2018. Publisher Site

33. Wilson HJ, Dickinson F, Hoffman DJ, et al. Fat free mass explains the relationship between stunting and energy expenditure in urban Mexican Maya children. Annals of human biology. 2012;39(5):432-9 Google Scholar

34. Victora CG, Adair L, Fall C, et al. Maternal and child undernutrition: consequences for adult health and human capital. Lancet. 2008;371(9609):340-57. Publisher Site Google Scholar

35. World Health Organization. Non-communicable diseases country profiles 2018. 2018. Publisher Site

36. Vaidya A, Pathak RP, Pandey MR. Prevalence of hypertension in Nepalese community triples in 25 years: a repeat cross-sectional study in rural Kathmandu. Indian heart journal. 2012;64(2):128-31. Google Scholar

37. Sharma SK, Ghimire A, Radhakrishnan J, et al. prevalence of hypertension, obesity, diabetes, and metabolic syndrome in Nepal. International journal of hypertension. 2011;2011. Publisher Site Google Scholar

38. Thienemann F, Ntusi NAB, Battegay E, et al. Multimorbidity and cardiovascular disease: a perspective on low- and middle-income countries. Cardiovasc Diagn Ther. 2020;10(2):376-85. Publisher Site Google Scholar

39. World Health Organization. Waist circumference and waist-hip ratio: report of a WHO expert consultation, Geneva, 8-11 December 2008. Publisher Site Google Scholar

40. Park S-H, Choi S-J, Lee K-S, et al. Waist circumference and waist-to-height ratio as predictors of cardiovascular disease risk in Korean adults. Circulation Journal. 2009;73(9):1643-50. Publisher Site Google Scholar

41. Zeng Q, He Y, Dong S, et al. Optimal cutoff values of BMI, waist circumference and waist: height ratio for defining obesity in Chinese adults. British Journal of Nutrition. 2014;112(10):1735-44. Google Scholar

42. Lee CMY, Huxley RR, Wildman RP, et al. Indices of abdominal obesity are better discriminators of cardiovascular risk factors than BMI: a meta-analysis. Journal of clinical epidemiology. 2008;61(7):64653. Publisher Site Google Scholar 
43. Caminha TC, Ferreira HS, Costa NS, et al. Waist-to-height ratio is the best anthropometric predictor of hypertension: a population-based study with women from a state of northeast of Brazil. Medicine. 2017;96(2). Publisher Site Google Scholar

44. Li W-C, Chen I-C, Chang Y-C, et al. Waist-to-height ratio, waist circumference, and body mass index as indices of cardiometabolic risk among 36,642 Taiwanese adults. Eur J Nutr. 2013;52(1):57-65.

Publisher Site Google Scholar

45. Sayeed M, Mahtab H, Latif Z, et al. Waist-to-height ratio is a better obesity index than body mass index and waist-to-hip ratio for predicting diabetes, hypertension and lipidemia. BangladeshMed Res Counc Bull. 2003;29(1):1-10. Google Scholar

46. Li N, Yang T, Yu W-Q, et al. Is waist-to-height ratio superior to body mass index and waist circumference in predicting the incidence of hypertension? Annals of Nutrition and Metabolism. 2019;74(3):215-23. Publisher Site Google Scholar

47. Sakurai M, Miura K, Takamura T, et al. Gender differences in the association between anthropometric indices of obesity and blood pressure in Japanese. Hypertension Research. 2006;29(2):75-80. Publisher Site Google Scholar

48. Bennasar-Veny M, Lopez-Gonzalez AA, Tauler P, et al. Body adiposity index and cardiovascular health risk factors in Caucasians: a comparison with the body mass index and others. PloS one. 2013;8(5):e63999. Publisher Site Google Scholar

49. Van Dijk S, Takken T, Prinsen E, et al. Different anthropometric adiposity measures and their association with cardiovascular disease risk factors: a meta-analysis. Netherlands Heart Journal. 2012;20(5):20818. Publisher Site Google Scholar

50. Center for Disease Control. About Adult BMI 2017. https://www.cdc.gov/healthyweight/assessing/bmi/adult_bmi/index.html. Accessed on 20 August 2020.

51. The IDF consensus worldwide definition of the metabolic syndrome. International Diabetes Federation (IDF): 2006. Publisher Site

52. Guagnano MT, Ballone E, Colagrande V, et al. Large waist circumference and risk of hypertension. International journal of obesity. 2001;25(9):1360-4. Google Scholar

53. Levine DA, Calhoun DA, Prineas RJ, et al. Moderate waist circumference and hypertension prevalence: the REGARDS Study. American journal of hypertension. 2011;24(4):482-8. Publisher Site Google Scholar

54. Rouf A, Rasool M, SM SK, et al. Prevalence of hypertension and its association with waist circumference in adult population of Block Hazratbal, Srinagar, India. Annals of Medical and Health Sciences Research. 2018. Google Scholar

55. Rezende AC, Souza LG, Jardim TV, et al. Is waist-to-height ratio the best predictive indicator of hypertension incidence? A cohort study. BMC public health. 2018;18(1):281. Publisher Site Google Scholar

56. Siani A, Cappuccio FP, Barba G, et al. The Relationship of Waist Circumference to Blood Pressure: The Olivetti Heart Study*. American journal of hypertension. 2002;15(9):780-6. Google Scholar 
57. Vikram NK, Latifi AN, Misra A, et al. Waist-to-height ratio compared to standard obesity measures as predictor of cardiometabolic risk factors in Asian Indians in North India. Metabolic syndrome and related disorders. 2016;14(10):492-9. Google Scholar

58. Prasad DS, Zubair K, Suganthy JP, et al. Appropriate anthropometric indices to identify cardiometabolic risk in South Asians. WHO South-East Asia journal of public health. 2013;2(3-4):142-8. Publisher Site Google Scholar

\section{Figures}

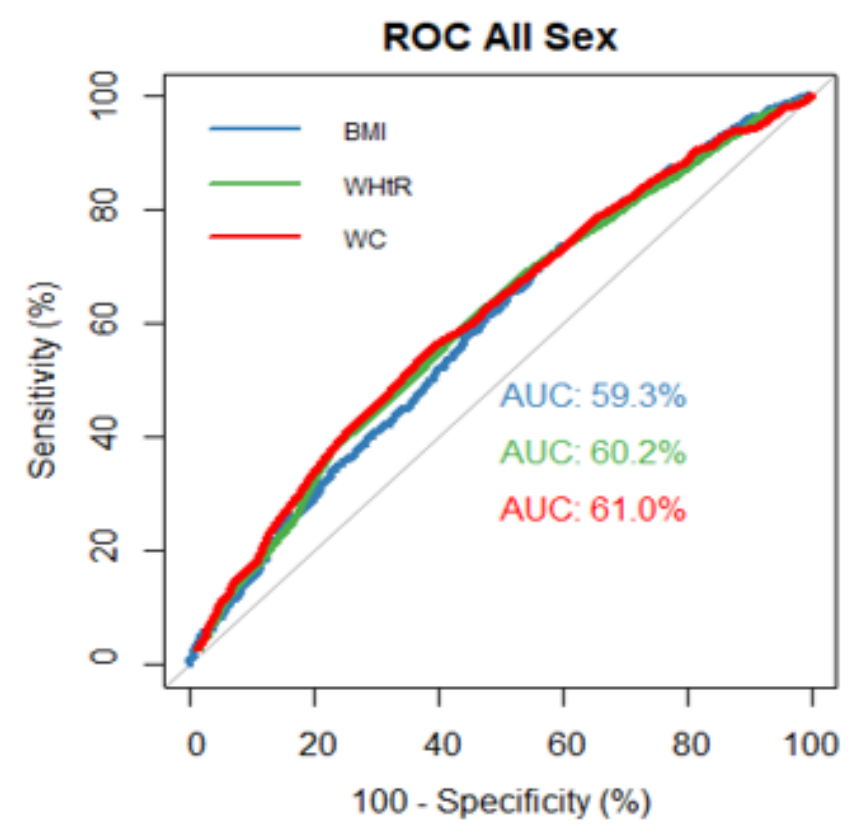

\section{Figure 1}

Comparison of the ROC curves of WC, WHR, and BMI in total participants 